\title{
Total antioxidant capacity in Mediterranean $\beta$-thalassemic patients
}

\author{
Ioannis Tsamesidis ${ }^{1, A-D}$, Claudio Fozza ${ }^{2, C-E}$, Eleni Vagdatli ${ }^{3, B}$, Anastasia Kalpaka ${ }^{4, B}$, Carla Cirotto ${ }^{5, B}$, Maria Carmina Pau ${ }^{1}$, B, \\ Antonella Pantale $0^{2, E}$, Francesco Turrini ${ }^{6}, \mathrm{E}$, Elisavet Grigoriou ${ }^{7, \mathrm{C}}$, Eugenia Lymperaki ${ }^{3, \mathrm{~A}-\mathrm{C}, \mathrm{F}}$ \\ ${ }^{1}$ Department of Medicine, Section of Internal Medicine, University of Verona, Italy \\ 2 Department of Biomedical Sciences, University of Sassari, Italy \\ ${ }^{3}$ Department of Medical Laboratories, Alexander Technological Educational Institute of Thessaloniki, Sindos, Greece \\ ${ }^{4}$ Saint Paul General Hospital, Thessaloniki, Greece \\ ${ }^{5}$ Blood Center, Servizio Trasfusionale, Ospedale Santissima Annunziata, Sassari, Italy \\ ${ }^{6}$ Department of Oncology, University of Turin Medical School, Turin, Italy \\ ${ }^{7}$ Department of Electrical Engineering and Electronics, University of Cagliari, Italy \\ A - research concept and design; $B$ - collection and/or assembly of data; $C$ - data analysis and interpretation; \\ $\mathrm{D}$ - writing the article; $\mathrm{E}$ - critical revision of the article; $\mathrm{F}$ - final approval of article
}

Address for correspondence

loannis Tsamesidis

E-mail:johntsame@gmail.com

\section{Funding sources}

This research was supported by Alexander Technological Educational Institute of Thessaloniki, Greece.

\section{Conflict of interest}

None declared

Received on November 30, 2015

Revised on March 03, 2016

Accepted on June 17, 2016

DOI

10.17219/acem/63746

\section{Copyright}

Copyright by Author(s)

This is an article distributed under the terms of the

Creative Commons Attribution Non-Commercial License

(http://creativecommons.org/licenses/by-nc-nd/4.0/)

\begin{abstract}
Background. Beta thalassemia major (BT) is an inherited blood disorder caused by reduced or absent synthesis of the hemoglobin beta chains, associated with profound anemia, jaundice, splenomegaly, expanded bone marrow volume, siderosis and cardiomegaly. Because of repeated blood transfusions, BT patients are subjected to peroxidative tissue injury due to secondary iron overload.

Objectives. The aim of the study was to analyze: 1) the total antioxidant capacity (TAC) value in BT patients (study group) and their healthy controls (control group) from Greece (Central Macedonia) and Italy (Sardinia); correlations between 2) the $T A C$ and ferritin levels of $B T$ patients, and 3) the TAC and ferritin values in BT patients with different chelation therapies;
\end{abstract}

Material and methods. The studied group consisted of 60 subjects diagnosed with BT (41 female, mean age: $41.5 \pm 9.5$ years) and 40 healthy controls matched with age and sex (31 female, mean age: $38.5 \pm 3.7$ years). Desferrioxamine (DFO) was the basic previous chelation regimen for all BT patients. Antioxidant activity was assayed spectrophotometrically, using a TAC Kit (Total Antioxidant Capacity Colorimetric assay kit, produced by Cayman (hemical Co.), and ferritin was assayed by immunoturbidimetry.

Results. Lower levels of TAC were observed in BT patients of both countries when compared with controls $(1.83 \mathrm{mmol} / \mathrm{L}$ vs $2.7 \mathrm{mmol} / \mathrm{L}$ in the Italian study group and controls and $2.42 \mathrm{mmol} / \mathrm{L}$ vs $3.2 \mathrm{mmol} / \mathrm{L}$ in the Greek study group and controls). There were no significant correlations between plasmatic TAC and ferritin. Furthermore, deferasirox was the only chelation treatment in which TAC showed a correlation in both regions.

Conclusions. Our results potentially suggest that the reduced levels of TAC detectable in BT patients could demonstrate their reduced antioxidant defensive mechanisms.

Key words: oxidative stress, $\beta$-thalassemia major, total antioxidant capacity, chelation therapies, Mediterranean countries 
Transfusion practice and chelation therapy are the cornerstones of the modern clinical management of patients with beta thalassemia (BT) major, and have substantially contributed to improving the outcomes in such patients. ${ }^{1}$ Nevertheless, iron overload remains a common complication, especially after long-term treatment. ${ }^{2,3} \mathrm{On}$ the one hand, it has been evident from previous studies that iron overload is the main causative agent responsible for the increased production of free radicals and reactive oxygen species (ROS), and the subsequent oxidative stress which is compensated for by various antioxidants present in the body. ${ }^{4}$ Oxidative stress occurs as a result of increased levels of lipid peroxides and free-radical intermediates, along with a decrease in total antioxidant capacity (TAC). ${ }^{5}$ On the other hand, the selection of proper iron chelatory agents can be helpful in the regulation of the antioxidant status in patients with BT major. Currently, there are 3 main iron-chelating agents available for continuous use in patients with thalassemia on regular transfusions, i.e. desferrioxamine (DFO), deferiprone (DFP) and deferasirox (DFX), which provide good results in reducing cardiac, hepatic and endocrine toxicity. ${ }^{6}$ Historically, the most widely-used chelator is DFO, which demonstrated a significant reduction in the morbidity and mortality of these patients by preventing or reducing the damage to key organs such as the heart, liver and endocrine glands. Two new-generation chelators such as DFP and DFX, which can be administered orally, have substantially improved compliance and quality of life of these patients. ${ }^{7}$ Oxidative stress and disturbances in the antioxidant balance have been studied extensively in BT major patients. ${ }^{8-11}$ The main purpose of this study was to investigate if there is any correlation between the plasmatic TAC and ferritin blood levels in BT patients of 2 Mediterranean regions such as Central Macedonia and Sardinia. We also evaluated the possible impact of different iron chelators in this setting.

\section{Material and methods}

\section{Patients and controls}

Table 1 has all the demographical and clinical characteristics of the study and control groups. Sixty $\beta$-thalassemic major individuals were included in the study: 30 Italian patients from Sardinia (group A, Servizio Trasfusionale, Ospedale Santissima Annunziata, Sassari), and 30 Greek patients from Central Macedonia (group B, Saint Paul General Hospital of Thessaloniki, Greece). The mean age of the patients was 42 and 41 (range 25-65) years in the 2 groups, respectively. There were 19 (63\%) females in group A (Italians) and 22 (73\%) in group B (Greeks). All subjects had given informed consent. The diagnosis of $\beta$-thalassemia major was made considering the results of hemoglobin electrophoresis and the clinical features of the patients. BT minor and intermediate cases were excluded. In addition, $26.6 \%$ of the study group was represented by healthy carriers of $\mathrm{HCV}$. The Italian and Greek patients were receiving an average dosage of iron chelators of $74 / 5 \mathrm{mg} / \mathrm{Kg}$ and 66.6 $\mathrm{mg} / \mathrm{kg}$, respectively, while they had been under chelation therapy for an average of 33.5 and 37.1 years, respectively. All the patients who underwent long-lasting transfusion therapy were under chelation therapy with one or more of the following medications: DFX, DFP or DFO. Six subgroups were considered in relation to the treatment modality, group A1 for the Italian study group using DFX (71\% female, mean age: $42.8 \pm 12.8$ years); A2 for those using DFP ( $85 \%$ female, mean age: $39.3 \pm 10$ years ); A3 for the Italian BT patients using DFO (50\% female, mean age: $43.7 \pm 4.6$ years); and A4 for those under DFX + DFO (50\% female, mean age: $42.85 \pm 7.7$ years) chelation treatment. The Greek study group B1 for the patients using DFX (72.7\% female, mean age: $44 \pm 10.3$ years) and B2 for those chelating with DFP (73.6\% female, mean age: $37 \pm 7.3$ years). Forty age- and sex-matched healthy subjects were enrolled in the study: 20 Italians (75\% female, mean age: $38.75 \pm 3.8$ years) from Sardinia and 20 Greeks (80\% female, mean age: $38.2 \pm 3.65$ age) (Central Macedonia). None of the study group and the control group members received any dietary supplementation for at least 6 months before the analysis.

\section{Blood sample collection}

Blood samples were obtained in the morning, before transfusional therapy, in EDTA-containing tubes. The average monthly transfusion for group A was $4.4 \pm 0.5$ times and for group B, $3.2 \pm 0.9$ times. The samples were centrifuged to divide the cellular components from the plasma, and stored at $-80^{\circ} \mathrm{C}$ until Trolox Equivalence Antioxidant Capacity (TEAC) was carried out.

\section{Measurement of parameters}

Antioxidant activity was assayed spectrophotometrically, using a TAC Kit (Total Antioxidant Capacity Colorimetric assay kit, produced by Cayman Chemical Co., Ann Arbor, USA) with the TEAC method in the clinical chemistry laboratory of the Alexander Technological Educational Institute, Thessaloniki, Greece. The levels of ferritin in both groups of patients had been measured previously by immunoturbidimetry. This technique is based on latex bound ferritin antibodies which react with the antigen in the sample to form an antigen/antibody complex, this is then measured turbidimetrically after agglutination. The obtained turbidity is proportional to the ferritin concentration and is determined at $700 \mathrm{~nm}$. Ferritin determinations were carried out in the biochemical laboratory of the Saint Paul General Hospital, Thessaloniki, Greece. 
Table 1. Demographical and clinical characteristic of study and control groups

\begin{tabular}{|l|c|c|c|}
\hline \multicolumn{1}{|c|}{ Parameters } & Italian study group & Greek study group & Italian controls \\
\hline Thalassemic major patients & 30 & 30 & 20 \\
\hline Age (average) & $42( \pm 8.9)$ & $41( \pm 10.2)$ & $38.2( \pm 3.65)$ \\
\hline Sex, female/male & $19 / 11$ & $22 / 8$ & $15 / 5$ \\
\hline HCV, positive * & 2 & 14 & - \\
\hline Monthly transfusion & $4.4( \pm 0.5)$ & $3.2( \pm 0.9)$ & - \\
\hline Average dosage of Iron chelators $(\mathrm{mg} / \mathrm{kg})$ & $74.5( \pm 32.1)$ & $66.6( \pm 30.9)$ & - \\
\hline Average years under chelation therapy & $33.5( \pm 5.8)$ & $37.1( \pm 7.07)$ & - \\
\hline
\end{tabular}

The values represent mean \pm standard error of the mean.

Table 2. Mean Total Antioxidant Capacity and ferritin levels of study group and control subjects

Part 1. Mean Total Antioxidant Capacity in control subjects

\begin{tabular}{|l|c|}
\hline $\begin{array}{c}\text { Study } \\
\text { groups }\end{array}$ & $\begin{array}{c}\text { Mean TAC } \\
(\mathrm{mmol} / \mathrm{L}) \\
(\mathrm{n}=20)\end{array}$ \\
\hline Italian controls & $2.7( \pm 0.7)$ \\
\hline Greek controls & $3.2( \pm 0.5)$ \\
\hline Mean controls* & $2.95( \pm 0.6)$ \\
\hline
\end{tabular}

${ }^{*} p=0.007$.

Part 2. Mean Total Antioxidant Capacity and ferritin levels of study group

\begin{tabular}{|l|c|c|c|c|}
\hline \multicolumn{1}{|c|}{$\begin{array}{c}\text { Study } \\
\text { groups }\end{array}$} & $\begin{array}{c}\text { Mean TAC } \\
(\mathrm{mmol} / \mathrm{L}) \\
(\mathrm{n}=30)\end{array}$ & $\begin{array}{c}\text { Mean ferritin } \\
(\mathrm{ng} / \mathrm{mL}) \\
(\mathrm{n}=30)\end{array}$ & r-value & p-value \\
\hline $\begin{array}{l}\text { Italian study } \\
\text { group } \\
\text { Greek study } \\
\text { group }\end{array}$ & $1.83( \pm 0.6)$ & $1817( \pm 72.2)$ & .115 & .546 \\
\hline $\begin{array}{l}\text { Mean study } \\
\text { group* }\end{array}$ & $2.42( \pm 0.5)$ & $1084( \pm 161.15)$ & .73 & .700 \\
\hline
\end{tabular}

${ }^{*} p=0.007$.

\section{Results}

The results of the study are shown in Tables 2 and 3 . Plasmatic TAC appeared to be significantly higher in control subjects compared to the study groups $(\mathrm{p}=0.007)$. No correlation existed between TAC and ferritin in either of the study groups $(\mathrm{r}=0.115 ; \mathrm{p}=0.546, \mathrm{r}=0.73$; $\mathrm{p}=0.700)$. Interestingly, there were positive correlations in the study subgroups based on their various chelation therapies. We observed positive correlations in the measurements of TAC between Italian study subgroups A1 and A3 ( $r=0.682 ; \mathrm{p}=0.046)$, and also between A1 and B1 ( $r=0.681 ; p=0.046)$. Clearly, patients of both coun- tries that are using deferasirox represent a good model of study because of their statistically significant results. Indeed, significant results were also observed between the ferritin measurements of study subgroups A2 and A3 $(r=0.663 ; p=0.036)$. Furthermore, a notable inverse correlation was seen between the ferritin levels and age of the Italian subgroup A3 $(r=-0.775 ; \mathrm{p}=0.024)$. Plasmatic TAC measurements of the patients under desferrioxamine showed statistically significant results without any statistically significant correlations with ferritin.

\section{Discussion}

Oxidative stress in BT patients activates various antioxidant enzyme systems to protect the body tissues from its damaging effects. Enzymatic and non-enzymatic antioxidants, either endogenous or exogenous, are known to counteract the deleterious effects of ROS (reactive oxygen species) and RNS (reactive nitrogen species), leading to protection against oxidative stress and RNS stress. ROS formation inside red blood cells (RBCs) is almost entirely due to methemoglobin (metHb) formation, but under normal steady-state conditions the RBC antioxidant systems can cope with such a threat. ${ }^{12,13}$ In thalassemia, iron mediated ROS formation, originating from imbalanced globin production and regular blood transfusions, can cause systemic tissue damage. ${ }^{7,14}$ Antioxidant status can be investigated individually by direct measurement inside the RBC of cytoprotective enzymes such as superoxide dismutase (SOD) and glutathione peroxidase (GSH-Px) ${ }^{15-18}$ In our experiments, we chose to measure TAC in plasma, as some studies suggest that assessing total plasmatic antioxidant capacity is more useful than measuring antioxidant individually, since their synergistic interactions could be determined. ${ }^{9,19,20}$

In the present study, we measured TAC in Greek and Italian patients, considering the high prevalence of BT 
Table 3. Total Antioxidant Capacity and ferritin levels of BT patients based on their chelation therapy

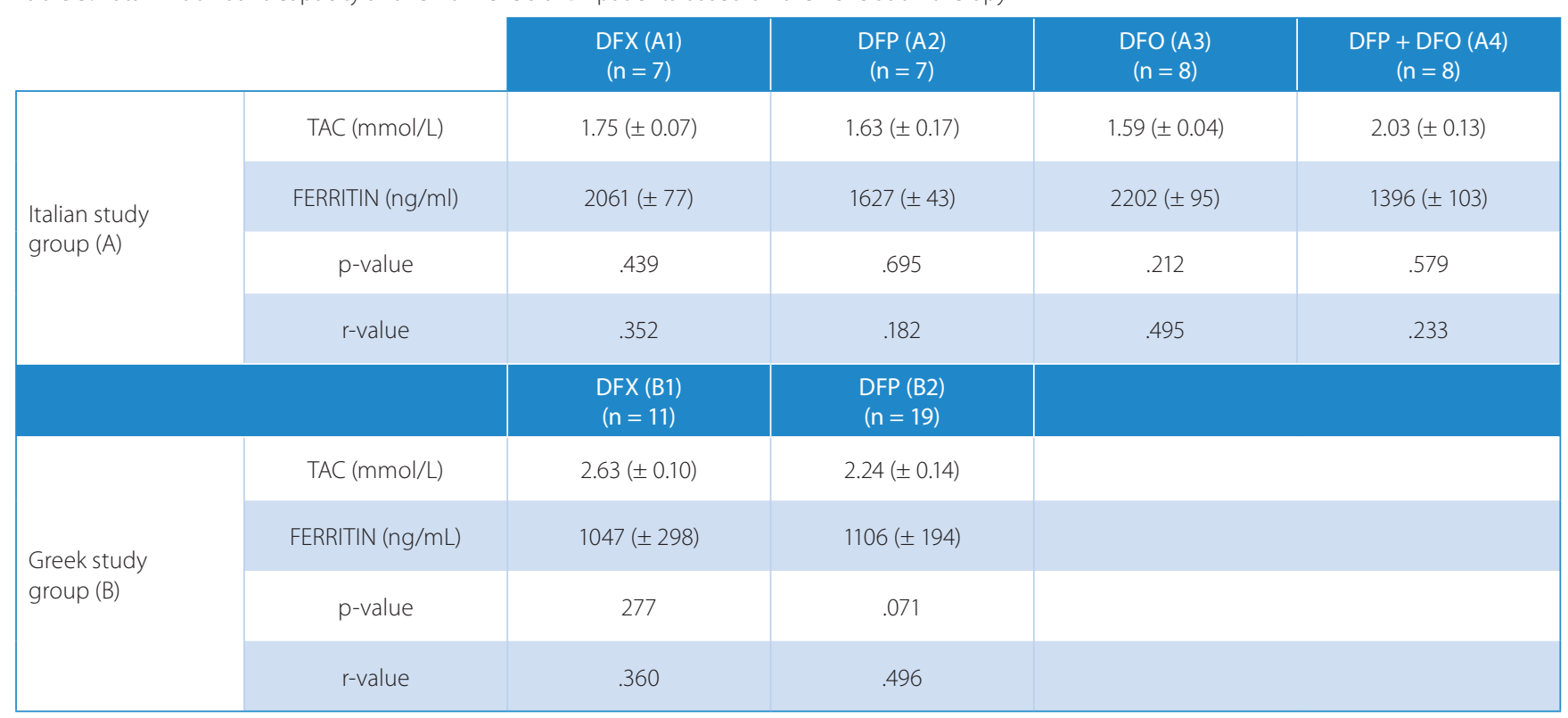

The values represent mean \pm standard error of the mean.

Part 2. Positive Correlations based on their chelation therapy

\begin{tabular}{|l|c|c|c|}
\hline \multicolumn{1}{l|}{} & $\begin{array}{c}\mathrm{A} 1+\mathrm{A} 3 \\
(\mathrm{TAC})\end{array}$ & $\begin{array}{c}\mathrm{A} 1+\mathrm{B} 1 \\
(\mathrm{TAC})\end{array}$ & $\begin{array}{c}\mathrm{A} 2+\mathrm{A3} \\
\text { (FERRITIN) }\end{array}$ \\
\hline p-value & .046 & .046 & .036 \\
\hline r-value & .682 & .681 & .663 \\
\hline
\end{tabular}

in these regions as well as the lack of studies analyzing and comparing the antioxidant status of patients from these Mediterranean countries. A single study by Hamed et al. showed a significant decrease in TAC in Italian BT patients when compared to normal controls. ${ }^{21}$ Our study confirmed the decreased levels of TAC not only in Italian but also in Greek BT patients. A different study by Bazvand et al., performed in Iranian patients on serum, showed increased antioxidant status in BT patients. A possible explanation for this unexpected antioxidant status detected in Iranian BT patients could be the different age range $(14.7 \pm 6.9)$ and/or chelation regimen. ${ }^{9}$

The reduced TAC of BT patients might be due to an increased utilization of antioxidants in order to counterbalance the effects of ROS, which may be involved in the pathological consequences of BT major and contribute to the gradual development of organ damage. ${ }^{10}$ The study would be strengthened if TAC evaluation was used in conjunction with other oxidative stress and antioxidant defense biomarkers, such as F2-isoprostanes. ${ }^{26}$ However further investigations are needed in order to gain a better understanding about its biological and therapeutic implications. In particular, prospective studies are needed to validate the use of plasmatic TAC in this clinical setting, as a useful tool to predict the risk of free radical-induced tissue damage.

\section{References}

1. Walter PB, Macklin EA, Porter J, et al. Inflammation and oxidant stress in $\beta$-thalassemia patients. Haematologica. 2008;93:817-825.

2. Zurlo MG, De Stefano P, Borgna-Pignatti C, et al. Survival and causes of death in thalassemia major. Lancet. 1989;2:27-30.

3. Vichinsky E, Butensky E, Fung E, et al. Comparison of organ dysfunction in transfused patients. American J Hematology. 2005;80:70-74.

4. Pavlova LE, Savov VM, Petkov HG, Charova IP. Oxidative stress in patients with $\beta$-thalassemia major. Prilozi. 2007;28:145-154.

5. Akça H, Polat A, Koca C. Determination of total oxidative stress and total antioxidant capacity before and after the treatment of irondeficiency anemia. J Clin Lab Anal. 2013;27:227-230.

6. Prus E, Fibach E. Effect of iron chelators on labile iron and oxidative status of thalassemic erythroid cells. Acta Haematologica. 2010;123:14-20.

7. Van Zwieten R, Verhoeven AJ, Roos D. Inborn defects in the antioxidant systems of human red blood cells. Free Rad Biol Med. 2014;67:377-386.

8. Awadallah S, Arrayed A, Bahareth E, Saeed Z. Total antioxidant capacity and ischemia modified albumin in beta thalassemia. Clin Lab. 2013;59:687-691.

9. Bazvand F, Shams S, Esfahani M, et al. Total antioxidant status in patients with major $\beta$-thalassemia. Iran J Ped. 2011;21:159-165.

10. Livrea MA, Tesoriere L, Pintaudi AM, et al. Oxidative stress and antioxidant status in $\beta$-thalassemia major: Iron overload and depletion of lipid-soluble antioxidants. Blood. 1996;88:3608-3614.

11. Ghone RA, Kumbar KM, Suryakar AN, Katkam RV, Joshi NG. Oxidative stress and disturbance in antioxidant balance in beta thalassemia major. Ind J Clin Biochem. 2008;23:337-340.

12. Fibach E, Rachmilewitz EA. The role of antioxidants and iron chelators in the treatment of oxidative stress in thalassemia. Annals of New York Academy of Sciences. 2010;202:10-16.

13. Richards RS, Roberts TK, Dunstan RH, McGregor NR, Butt HL. Erythrocyte antioxidant systems protect cultured endothelial cells against oxidant damage. Biochem Mol Biol Int. 1998;46:857-865.

14. Sengsuk C, Tangvarasittichai O, Chantanaskulwong P, et al. Association of iron overload with oxidative stress, hepatic damage and dyslipidemia in transfusion-dependent $\beta$-thalassemia/ $\mathrm{HbE}$ patients. Ind J Clin Biochem. 2014;9:298-305.

15. Shazia Q, Mohammad ZH, Rahman T, Shekhar HU. Correlation of oxidative stress with serum trace element levels and antioxidant enzyme status in beta thalassemia major patients. Anemia. 2012;2012:7.

16. Kalpravidh RW, Siritanaratkul N, Insain P, et al. Improvement in oxidative stress and antioxidant parameters in $\beta$-thalassemia/ $\mathrm{HbE}$ patients treated with curcuminoids. Clin Biochem. 2010;43:424-429. 
17. Van Zoeren-Grobben D, Lindeman JH, Houdkamp E, Moison RM, Wijnen JT, Berger HM. Markers of oxidative stress and antioxidant activity in plasma and erythrocytes in neonatal respiratory distress syndrome. Acta Paediatrica. 1997;86:1356-1362.

18. Roos D, Eckmann CM, Yazdanbakhsh M, Hamers MN, de Boer M. Excretion of superoxide by phagocytes measured with cytochrome entrapped in released erythrocyte ghosts. J Biol Chem. 1984;10:1770-1775.

19. Kampa M, Nistikaki A, Tsaousis V, Maliaraki N, Notas G, Castanas E. A new automated method for the determination of the Total Antioxidant Capacity (TAC) of human plasma, based on the crocin bleaching assay. BMC Clin Pathol. 2002;2:3.

20. Erel O. A novel automated direct measurement method for total antioxidant capacity using a new generation, more stable ABTS radical cation. Clin Biochem. 2004;37:277-285.

21. Hamed EA, Elmelegy NT. Renal functions in pediatric patients with beta-thalassemia major: Relation to chelation therapy: Original prospective study. Italian J Pediatrics. 2010;25:36-39.

22. Veríssimo MP, Loggetto SR, Fabron Junior A, et al. Thalassemia Association protocol for iron chelation therapy in patients under regular transfusion. Revisa Brasileira de Hematologia e Hemoterapia. 2013;35:428-434.

23. Hori A, Mizoue T, Kasai $\mathrm{H}$, et al. Body Iron Store as a predictor of oxidative DNA damage in healthy men and women. Cancer Science. 2010;101:517-522.

24. Jomova K, Valko M. Importance of iron chelation in free radicalinduced oxidative stress and human disease. Current Pharmaceutical Design. 2011;17:3460-3473.

25. Yanpanitch OU, Hatairaktham S, Charoensakdi R, et al. Treatment of $\beta$-thalassemia/hemoglobin $E$ with antioxidant cocktails results in decreased oxidative stress, increased hemoglobin concentration and improvement of the hypercoagulable state. Oxidative Medicine and Cellular Longevity. 2015;2015:8.

26. Rivara MB, Ikizler TA, Ellis CD, Mehrotra R, Himmelfarb J. Association of plasma F2-isoprostanes and isofurans concentrations with erythropoiesis-stimulating agent resistance in maintenance hemodialysis patients. BMC Nephrology. 2015;16:74-79. 